\section{The effects of complexity and uncertainty upon performance at a problem-solving task*}

\author{
D. R. DAVIES, V. J. SHACKLETON, and LESLEY LANG \\ University of Wales Institute of Science and Technology, Cardiff, Wales
}

Three groups of $10 \mathrm{Ss}$ performed a self-paced problem-solving task involving four levels of complexity. For Group 1 the order of presentation of the problems was in increasing order of complexity, for Group 2 in decreasing order, while for Group 3 it was apparently random. Ss were aware of the method of presentation and were also asked to rate their feelings towards the task on six 7-point scales during the task. Results showed that solution times were significantly faster in Group 3, and there was a nonsignificant tendency for Ss in this group to have lower boredom scores. The results are interpreted as providing some support for the effects of "uncertainty" upon efficiency and task involvement.

It has long been recognized that varied stimulation is important to the well-being and efficiency of an organism (Hebb, 1955). More specifically, performance at a task has been shown to be better when $S$ is in a "stimulating" or "arousing" situation, and such backgrounds as music (McGrath, 1963) and white noise (Broadbent, 1971) have been used in work in this area. Less well researched has been the effect of varied task structure and its relation to task efficiency and feelings toward the task.

The present study is concerned with the order of presentation of task elements in a problem-solving situation, similar to that used by Corcoran (1964). The task elements are blocks of problems varying in complexity, and three orders of presentation are used-" ascending c omplexity,", "descending complexity,", and "random presentation." It was argued that Ss would find the "random presentation" order more "interesting" and less "boring" and that their efficiency would be higher than that of Ss in the other two groups, since their "uncertainty" about the task would be greater and their experience of it more varied.

\section{METHOD}

The Ss were 30 university students, 14 men and 16 women, between 18 and 24 years of age; they were paid to take part in the experiment. Ss, who were tested individually, worked at the self-paced problem-solving task for varying times, averaging about $30 \mathrm{~min}$.

Each $S$ sat alone in a small room facing a screen, with both hands resting in front of a panel of six keys.

* The research reported here is supported by Research Grant HR833/1 from the U.K Social Science Research Council to the senior author.
Seventeen practice slides, each containing six symbols, were presented for inspection. Ss were instructed to select a single symbol in accordance with certain rules. These rules were the same as those used by Corcoran (1964) and were as follows: (1) choose black rather than white, (2) choose large rather than small, (3) choose squares rather than circles, and (4) choose up positions rather than down positions. Each rule was equally important, so that $S$ had to select from among the six symbols the one with the greatest number of positive attributes, indicating which symbol this was by pressing the key corresponding to it. The time taken to solve each problem and the key pressed (i.e., symbol chosen) were recorded automatically. The next slide then came on.

Eighty slides were viewed in the main experiment in four blocks of 20 . The 30 Ss were divided into three groups according to the order of presentation. In Group 1 the first 20 slides involved one rule, the second 20 slides two rules, and so on (this is called the "ascending complexity" condition). Group 2 received slides in the opposite order ("descending complexity" condition). In Group 3 slides involving one, two, three, and four rules were presented in the blocks in a predetermined random sequence (random condition). The Ss were aware of this procedure before the experiment began but had no knowledge of results apart from the practice slides. Between each block of slides, Ss rated their feelings towards the task on six 7-point scales and estimated task duration. The six subjective measures were boredom, concentration, effort, difficulty, daydreaming, and interest.

Thus, both the complexity and the "uncertainty" of the task were varied. The complexity variable was the amount of information which had to be processed, which increased as the number of rules required increased. The "uncertainty" variable consisted of changing the order of presentation of these rules.

\section{RESULTS AND DISCUSSION}

\section{Solution Times}

A trend analysis on solution times (ST) showed a significant effect of complexity level on ST $(p<.01)$, with ST increasing as complexity increases, and a significant effect of presentation order ("uncertainty") on ST ( $<<.05$ ), accounted for by the significantly shorter ST of the random group. Thus, in the two sequence groups, ST depended on complexity level, but a random presentation of problems appears to reduce overall $\mathrm{ST}$ and to reduce the difference in time taken to solve problems at different levels of complexity. No significant practice or fatigue effects were apparent.

Correct Solutions

A trend analysis on the number of correct solutions showed no significant difference between the groups but a significant increase in errors at the higher complexity levels $(p<.01)$.

Thus, the results show that the major determinants of both ST and accuracy was the level of task complexity, i.e., the number of rules that had to be considered in making a judgment. However, Ss who experienced high task uncertainty (the random group) exhibited faster ST than Ss in either of the other two groups who each carried out the task in a predetermined sequence. This faster ST was not achieved at the cost of making more errors.

\section{Subjective Measures}

A trend analysis showed no significant treatment effect on level of perceived difficulty but revealed that Ss perceived the task as being significantly more difficult $(p<.01)$ as task complexity increased. Analysis of the boredom rating scale scores showed that boredom was not affected by either time spent at the task or complexity level and that the sequence groups did not differ in amount of boredom reported. There was, however, a nonsignificant tendency for Ss in the high uncertainty group to have lower boredom scores than Ss in the other two groups.

A trend analysis of time estimation data showed no significant differences between the three groups but a significant effect $(p<.01)$ of smaller discrepancies between estimated time and actual time, with time at the task, for all three groups. That is, Ss in all three groups became more accurate at time estimations with time at the task. A chi-square test on the number of Ss overestimating and underestimating the actual time showed no significant difference in the frequency of 
Table 1

Rank Correlation Matrix of Subjective Ratings

\begin{tabular}{|c|c|c|c|c|c|}
\hline & Interest & $\begin{array}{c}\text { Day- } \\
\text { dreaming }\end{array}$ & Difficulty & Trying & $\begin{array}{l}\text { Concen- } \\
\text { trating }\end{array}$ \\
\hline Daydreaming & -0.14 & & & & \\
\hline Difficulty & $-0.34^{*}$ & $0.33^{*}$ & & & \\
\hline Trying Hard & $0.65+$ & $-0.49^{*}$ & $-0.31 *$ & & \\
\hline Concentrating & $0.59+$ & $-0.48+$ & $-0.31 *$ & $0.88 \dagger$ & \\
\hline Boredom & $-0.40^{*}$ & $0.40^{*}$ & $0.37 *$ & $-0.65+$ & $-0.57+$ \\
\hline
\end{tabular}

$*_{p}<.05 \quad+p<.01$

occurrence of either measure between the three groups.

The six subjective measures of feelings towards the task were correlated (Spearman's rank) for the whole population over the whole session. The $r$ values and probability levels are shown in Table 1. It can be seen from the matrix that all the measures but one are significantly correlated with each other. Time estimations did not correlate with any of the subjective responses.

The subjective report data suggest, therefore, that Ss who were most bored found the task more difficult, tended to daydream more, but did not concentrate as hard or expend as much effort as other Ss, all of which accords well with common sense. However, there was a tendency for Ss in the high uncertainty group to have lower boredom scores than Ss in the other two groups. Thus, uncertainty appears to exert a beneficial effect on task efficiency and possibly, too, on feelings towards the task.

$$
\text { REFERENCES }
$$

BROADBENT, D. E. Decision and stress. New Y ork: A cademic Press, 1971.

CORCORAN, D. W. J. The influence of task complexity and practice on performance after loss of sleep. Journal of Applied Psychology, 1964, 48, 339-343

HEBB, D. O. Drives and the c.n.s. (conceptual nervous system). Psychological Review, 1955, 62, 243-253. McGRATH, J. J. Irrelevant stimulation and vigilance performance. In $D$. N. Buckner and J. J. McGrath (Eds.), Vigilance: A symposium New York: McGraw-Hill, 1963. Pp. 3-21. 